\title{
Selectivity of Range Grass Seeds by Local
}

\section{Birds}

\section{CARL J. GOEBEL AND GREGG BERRY}

Highlight: A study was completed in depleted semiarid Pacific Northwest range to determine types of seeds preferred by local roosting birds. It was found that of the species tested, the two smallseeded species of Sherman big bluegrass and sheep fescue were removed more frequently than the larger-seeded wheatgrasses. The introduced annuals, cheatgrass and medusahead, were least removed of all species tested. Local birds can thus contribute to continued degradation of range communities by their seed diet preferences.

Broadcast aerial seeding on depleted rangelands has been especially appealing to range managers. If successful, costs would be much lower than if mechanical seeding techniques were used. There are many range areas in which mechanized equipment is not practical to use because of steepness or rockiness, or a combination of both. Broadcast seeding might also be accomplished on many ranges earlier in the season, before it is physically possible to reseed with mechanical equipment. Thus, seedings could often be made earlier, to better utilize the frequently limited moisture supply.

Although not generally recognized or identified, the influence of birds upon broadcast seedings can be significant. This factor alone may account for almost complete destruction of a potentially successful reseeding (Nelson et al., 1970). Managers normally do not observe bird activity at its peak, possibly because of disruption of bird activity while workers are present. Inadequate knowledge of bird habits, however, is probably the greatest source of inaccuracies in determining the magnitude of this problem.

Identifying the species and population densities of birds responsible for seed depredation is difficult. Adequate sampling techniques have not been available in the past, although some procedures are now being reported (Hooper et al., 1973/ Noble and Shepperd, 1973).

Of the studies reported upon bird depredation of seedings, most work concerns forest seedings. Mann (1968) stated that broadcast seeding attempts in the south before the 1950's were nearly always defeater by seed-eating animals-chiefly birds; but small mammals and insects also contributed to the seeding failures. Royall and Ferguson (1962) reported results which indicated that birds were the controlling factor in longleaf pine (Pinus palustris, Mill.) seeding establishment. Spencer (1954,

\footnotetext{
Authors are professor and range scientist, Washington State University, Pullman; and range conservationist, Bureau of Land Management, Susanville, California.

The report is Scientific Paper 4509, Project 0019, College of Agriculture Research Center, Washington State University, Pullman.

Manuscript received November 14, 1975
}

1958, and 1959), who has worked extensively on bird and mammal seed protectants for range and forest seedings, has concluded that damage by birds, small rodents, and insects is so extensive at times that some failures have resulted.

\section{Study Areas}

Seed-preference studies were conducted on range sites near Asotin, Wash., during the spring of 1969 (Fig. 1). The residual vegetation was typical of depleted semiarid ranges of the Pacific Northwest, where seeding of desirable species naturally or artifically is desired. These sites are dominated by cheatgrass (Bromus tectorum) and soft chess (B. mollis), with Sandberg bluegrass (Poa secunda) the dominant perennial. Medusahead (Taeniatherum asperum) may partially or completely replace other more desirable species. Bluebunch wheatgrass (Agropyron spicatum) was formerly dominant, but remains only as a relic. The vegetation, before depletion, was the Agropyron-Poa habitat type (Daubenmire, 1942). Annual precipitation averaged 33 $\mathrm{cm}$ and occurred most abundantly from October through May. Soils are silt loam in texture and shallow Asotin-silt loam, 61 to $66 \mathrm{~cm}$ deep over fragmented basalt.

Bird species and density were observed in the vicinity of the Asotin test site of approximately two hectares. Relative abundance was derived by the method recommended by Dice (1930). Four counts were made in August and three in March. Abundance is expressed as a density index number based on the time spent examining a given area. Density indices observed are presented in Table 1.

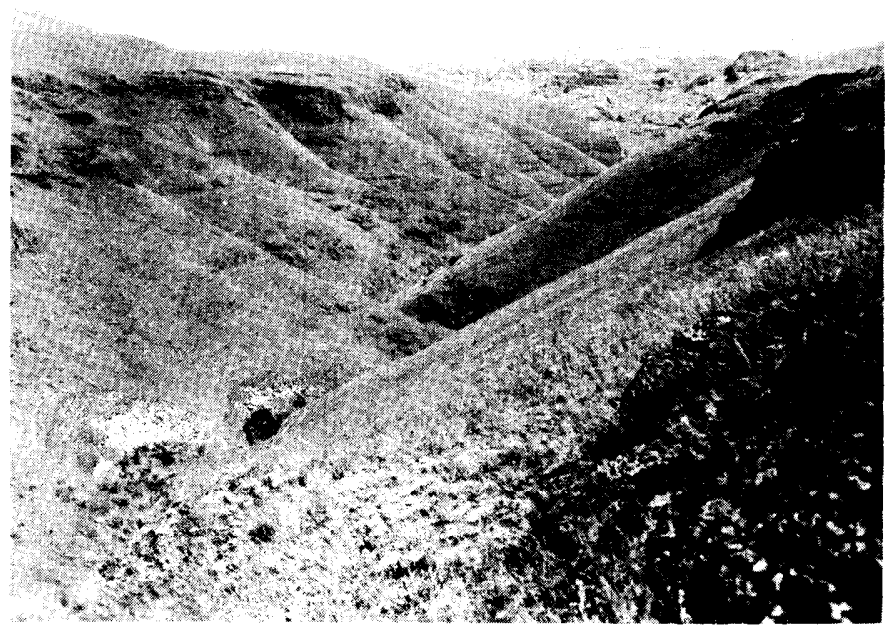

Fig. 1. Rangelands representative of steep rocky areas where broadcast seeding may aid re-establishment of desirable species within a reasonable period. 
Table 1. Density indices of birds observed in the vicinity of the Asotin study area.

\begin{tabular}{lcc}
\hline Bird species & Study area & $\mathbf{8 . 0 \mathrm { km } \text { transect }}$ \\
\hline Red tailed hawk & 0.4 & 2.1 \\
Marsh hawk & 0.3 & 3.1 \\
Sparrow hawk & 0.4 & 1.3 \\
California quail & & 0.4 \\
Ringnecked pheasant & 1.7 & 0.2 \\
Chukar & & 4.2 \\
Mourning dove & 2.7 & 2.8 \\
Short eared owl & & 3.8 \\
Eastern kingbird & & 0.5 \\
Western kingbird & 1.0 & 1.4 \\
Bank swallow & 0.3 & 4.7 \\
Barn swallow & 1.4 & 2.1 \\
Cliff swallow & 0.2 & 5.2 \\
Magpie & & 2.1 \\
Crow & & 0.2 \\
Rock wren & & 0.6 \\
Robin & 0.3 & 2.3 \\
Starling & 0.2 & 1.4 \\
House sparrow & 0.5 & 3.2 \\
Western meadow lark & 2.4 & 5.3 \\
Brewer blackbird & & 0.8 \\
Vesper sparrow & 1.1 & 0.2 \\
Lark sparrow & 0.3 & 2.3 \\
White crowned sparrow & 0.3 & 1.2 \\
Song sparrow & & 0.5 \\
\hline
\end{tabular}

Wild birds had access to seeds cafeteria-style on the range sites during the spring of 1969 . Feeding stations were established $11 / 3 \mathrm{~m}$ above the ground, complete with a roosting area. Stands were used because of the higher density of roosting birds in the study area. Feeding trials continued from early March, when travel to the area was first possible, until late spring, when the predominant birds apparently changed their diet from seeds to insects or other forms of food.

Seeds of species made available to the wild birds included six grass species. These were Whitmar beardless wheatgrass (Agropyron inerme), Greenar intermediate wheatgrass $(A$. intermedium $)$, thickspike wheatgrass $(A$. dasystachum), Luna pubescent wheatgrass $(A$. trichophorum), Sherman big bluegrass (Poa ampla), and sheep fescue (Festuca ovina). For comparison, seeds of the annuals, cheatgrass and medusahead, were also available.

Ten grams of seed of each grass species was randomly placed in the feeding stand. Remaining seeds were weighed weekly throughout the study period. Before weighing, all debris was removed from the remaining seed. Seed was made available beginning in early March until the 1st of June. After May 1 no utilization of seed occurred, even though the seed was made available until June 1.

\section{Results and Discussion}

There was some variation in the amount of seed removed by birds over the period of the study (Table 2 ). In general, the

Table 2. Average percent removal of grass seeds by roosting birds during the Spring 1969 seeding period near Asotin, Wash.

\begin{tabular}{|c|c|c|c|c|c|c|c|c|}
\hline \multirow{3}{*}{ Species } & \multicolumn{8}{|c|}{ Date of sample } \\
\hline & \multicolumn{3}{|c|}{ March } & \multicolumn{4}{|c|}{ April } & \multirow[b]{2}{*}{ Average } \\
\hline & 14 & 21 & 28 & 4 & 11 & 18 & 24 & \\
\hline \multicolumn{9}{|l|}{ Perennials } \\
\hline Sherman big bluegrass & 98 & 13 & 99 & 39 & 45 & 18 & 83 & 67 \\
\hline Sheep fescue & 81 & 3 & 98 & 39 & 43 & 69 & 40 & 53 \\
\hline Intermediate wheatgrass & 55 & 30 & 82 & 26 & 25 & 60 & 51 & 47 \\
\hline Thickspike wheatgrass & 67 & 10 & 99 & 11 & 8 & 30 & 5 & 33 \\
\hline Pubescent wheatgrass & 10 & 15 & 6 & 19 & 18 & 85 & 30 & 26 \\
\hline Bluebunch wheatgrass & 3 & 4 & 97 & 8 & 11 & 7 & 5 & 19 \\
\hline \multicolumn{9}{|l|}{ Annuals } \\
\hline Cheatgrass & 11 & 13 & 11 & 9 & 9 & 18 & 18 & 13 \\
\hline Medusahead & 3 & 3 & 12 & 2 & 3 & 14 & 11 & 7 \\
\hline
\end{tabular}

small-seeded Sherman big bluegrass seed was removed at a significantly faster and more consistent rate than any wheatgrasses tested. This was in sharp contrast to an earlier study (Nelson et al., 1970) in which the Sherman big bluegrass seed within treatments retaining litter showed little removal by bird depredation, while $93 \%$ of the broadcast wheatgrass seed had been removed. Thus, when available free-choice, there does not appear to be any natural color or taste deterrent in Sherman big bluegrass seed to consumption by local roost birds. The small size of the seed probably explains why this bluegrass has been successfully broadcast under certain range reseeding practices in which litter remained in place and competition had been chemically controlled.

Sheep fescue, another relatively small-seeded species, was also removed readily by birds. Although not as desirable a forage species as Sherman big bluegrass on range sites, nevertheless, it could be used in reseedings to maintain a litter cover that would hide small-seeded species from most birds until germination.

The Agropyron seed most preferred by birds tested was the intermediate wheatgrass. On an average, one-third of the thickspike and pubescent wheatgrass was removed during the course of the study. Except for two feeding periods, beardless bluebunch wheatgrass was consistently less preferred than any of the other wheatgrasses studied.

The annuals, cheatgrass and medusahead, on the average were removed in much smaller amounts than most of the perennials, especially during the early phases of the study. These averages were significantly less than the small-seeded species at the .05 level. Twice as much cheatgrass seed was removed by birds as medusahead.

This study substantiates that seed of desirable forage grass species is preferred by birds over the annual grass species abundantly found in the area. Thus, local bird preferences could indirectly contribute to the degradation of a range community. While domestic grazing animals may be consuming established plants of the more palatable species, birds may intensity the degradation of the community by consuming seed that is produced by the native bunchgrass or desirable forage species.

Medusahead, which is seldom grazed by domestic animals, especially after the development of awns, has an advantage over cheatgrass (seed stages) on normal density bird ranges. Since medusahead seeds appear to be less preferred than cheatgrass seeds, the additional advantage of fewer seeds consumed by birds may result in further replacement of cheatgrass by the less desirable medusahead in areas where both are adapted.

\section{Summary}

The results of this study are applicable on steep and/or rocky range sites which may not be artificially revegetated except by broadcast seeding.

It was found that approximately 25 species of birds inhabit the area during the spring reseeding period. When grass seeds were made available "cafeteria-style" it was found that the two small-seeded species, Sherman big bluegrass and sheep fescue, were removed more frequently than the larger-seeded wheatgrasses. The annuals, cheatgrass and medusahead, were least removed of all species tested. It was established that no natural repellent quality exists for the small-seeded species tested. In addition, birds may inhibit improvement of range sites by their seed diet preference for seeds of the perennial species tested. 


\section{Literature Cited}

Daubenmire, R. F. 1942. An ecological study of the vegetation of southeastern Washington and adjacent Idaho. Ecol. Monogr. 12:53-79.

Dice, L. P. 1930. Methods of indicating relative inventory of birds. Auk 17:22-24

Hooper, R. G., Crawford, H. S., and R. F. Harlow. 1973. Bird density and diversity as related to vegetation in forest recreational areas. J. Forest. 71:766-769.

Mann, W. F. 1968. Ten years experience with direct-seeding in the south. J. Forest. 66:828-833.

Nelson, J. R., A. M. Wilson, and C. J. Goebel. 1970. Factors influencing broadcast seeding in bunchgrass range. J. Range Manage. 23:163-170. Noble, D. L., and W. D. Shepperd. 1973. Grey-headed juncos: Important in first season mortality of Engelmann spruce. J. Forest. 71:763-765.

Royall, W. L., and E. R. Ferguson. 1962. Controlling bird and mammal damage in direct-seeding loblolly pine in east Texas. J. Forest. 60:37-39.

Spencer, D. A. 1954. Rodents and direct seeding. Symposium on rodent control research in direct seeding of forest and rangelands. J. Forest. 52:824-826.

Spencer, D. A. 1958. Prevention of mammal damage in forest management. Soc. Amer. Forest., Proc. p. 183-185.

Spencer, D. A. 1959. Direct seeding in the south. Symposium on seed protectants for direct seeding. Duke Univ. School of Forest. p. 62-66.

Steel, Robert G. D., and James H. Torrie. 1960. Principles and procedures of statistics. McGraw-Hill Book Co., Inc., New York, N.Y. 